\title{
White senior academics still resist recognizing racism
}

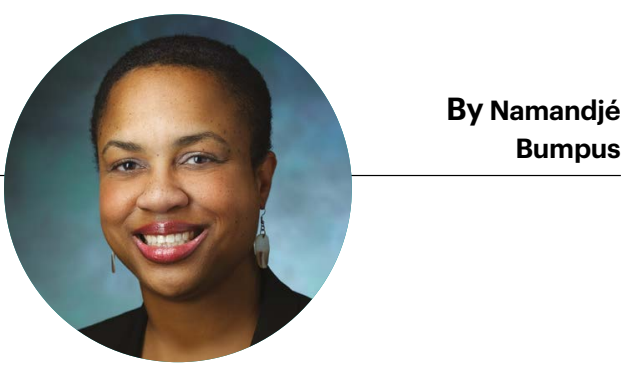

\section{As a Black woman who is the chair of a university science department, people have questioned my right to exist at every stage.}

\section{1

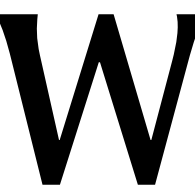

hy did we let you in, then?" That was what a white colleague in a scientific society asked me when I declined to lead a new diversity initiative. I am the first Black woman to chair a department at the Johns Hopkins University School of Medicine, and the only one currently leading a department of pharmacology at any US medical school. All through my career, from grade school onwards, teachers, colleagues and leaders have challenged my place in science. When my appointment as chair was announced, I received a racist backlash through Twitter and e-mail.

Some anti-Blackness I've faced has been indisputable. Someone wrote the ' $\mathrm{n}$-word' on an announcement of a scientific award that I had received, and left it in the inbox at the door to my lab. This is just one of several notes with a racial slur that I've received during my years in science.

White colleagues - initially flabbergasted at hearing about a racist incident I've faced - often follow up with denial and a desire to look outwards, but not inwards. Some have tried to explain the racism by making it my fault and insisting that I "must have done something" to bring it on. Others have reached out to tell me that what happened "actually wasn't that bad" or "we have all put it behind us". The 'we' is not meant to include me, yet insinuates that if I am to be a member of the community, I must move on at the same pace. People who knew about that note asserted only months later that they had never seen racism in academia. These are all acts of erasure of Black experience.

Part of the centring of whiteness in academia is that white faculty members are deemed the arbiters of the existence, validity and impact of racism: racism exists when white people say it does. As a result, racism is often disregarded and excused in academic institutions, at the expense of Black people.

I call on over-represented people in science who are expressing outrage about racism in broader society to focus the same level of energy on looking inwards, to wake up to how the culture in academic science is exclusionary. We debate the most exciting technology to bring to our departments to accelerate discovery; we should apply the same spirit to examining the culture of the department and improving how people are treated, because that, too, accelerates discovery. Leaders and faculty members must approach creating an anti-racist culture with the same vigour we apply to achieving every other dimension of scientific excellence.

\section{1 \\ We must \\ approach \\ creating an \\ anti-racist culture with \\ the same vigour we apply to every other dimension of scientific excellence."}

Namandjé Bumpus is director of the Department of Pharmacology and Molecular Sciences at the Johns Hopkins University School of Medicine in Baltimore, Maryland. e-mail:nbumpus1@ jhmi.edu
Too often, the response to anti-Blackness in academia is to instruct Black students, fellows, staff and faculty members to simply 'fix' their feelings, rather than demand transformation of the institution. I have been counselled to "develop a thick skin about these incidents" and told that if I speak up, I will jeopardize my career. Every time I have received a scientific award or grant since my graduate studies, I have been told by members of faculty that my achievements are bestowed on me merely because I am Black. I promised myself a long time ago that I will always speak up in these situations, so I reply: “That implies that you cannot envision a scenario where a Black person is the strongest candidate." I want people to think about what they are actually saying.

I also want people to recognize intersectionality - the complex and cumulative effect of multiple systems of oppression acting in concert. Volunteers compiling lists of female scientists and Black and Latinx scientists asked me to be on the latter, but not the former, as if being Black and a woman were mutually exclusive. Until I questioned them, they had not realized that when they were making efforts to help female scientists, their image was of white women.

I've had supporters, too. My lab tries to understand how metabolism by gut enzymes, such as the cytochromes P450, explains variability in how well drugs work, particularly for HIV. During my graduate studies, I struggled for about six months on an experiment to measure an uncharacterized metabolite. My adviser told me: "If there is anyone who can get it to work, it is you." That meant a lot, and I did get it to work. That kind of support, which I have also received from my postdoc adviser, current dean and others, fuels me through the nonsense I regularly deal with.

Too many people resist recognizing racism because they want to say, "We are all good people." I say, being good means learning to recognize racism and exclusionary culture, and then taking action. That means seeking out those who are often overlooked or actively excluded, nominating Black scientists, including students and postdocs, for awards and prominent speaking engagements. It means inviting Black scientists to give departmental talks. It means creating institutional transition programmes to help Black postdocs and other emerging scientists from historically marginalized groups to move into well-resourced faculty positions.

It also means leading by example. We've seen people, from graduate students to the head of the US National Institutes of Health, refuse to serve on 'manels' - panels made up entirely of cisgender men. Why not also commit to speak only at scientific conferences and on panels that feature Black voices or those from other historically marginalized groups? Tangible activism, not slogans or defensiveness, is what will strengthen science now. 